\title{
A Methodology for Mapping the Patient Journey for Noncommunicable Diseases in Low- and Middle-Income Countries
}

This article was published in the following Dove Press journal: Journal of Healthcare Leadership

\author{
Tanaya Bharatan, (D) \\ Ratna Devi, (D) ${ }^{2,3}$ Pai- \\ Hui Huang, (D) ${ }^{4}$ Afzal Javed, ${ }^{5}$ \\ Barrett Jeffers, ${ }^{6}$ \\ Peter Lansberg, (iD ${ }^{7}$ \\ Kaveri Sidhu, (D) \\ Kannan Subramaniam (iD) ${ }^{8}$ \\ 'Research Development \& Medical, Upjohn \\ Division, Pfizer Ltd, Mumbai, India; ${ }^{2}$ Executive \\ Office, Daksham A Health and Education, \\ Gurgaon, India; ${ }^{3}$ International Alliance of \\ Patient Organizations, London, UK; ${ }^{4}$ Medical \\ Affairs, Viatris, Taipei, Taiwan; ${ }^{5}$ Warwick \\ Medical School, University of Warwick, \\ Warwick, UK; ${ }^{6}$ Medical Affairs, Viatris Inc, \\ New York, NY, USA; ${ }^{7}$ Department of \\ Pediatrics, University Medical Center, \\ Groningen, the Netherlands; ${ }^{8}$ Medical Affairs, \\ Viatris | Mylan New Zealand Ltd, Auckland, \\ New Zealand
}

\section{Video abstract}

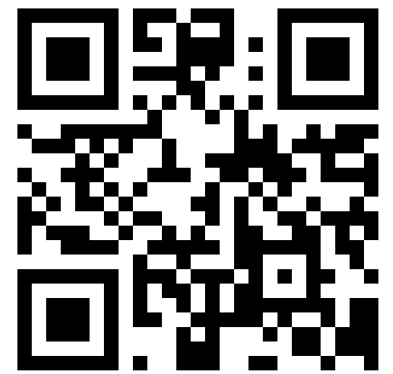

Point your SmartPhone at the code above. If you have a QR code reader the video abstract will appear. Or use: https://youtu.be//pYx9ul KT]k

Correspondence: Kannan Subramaniam Viatris | Mylan New Zealand Ltd, PO Box 1 I 183 , Ellerslie, Auckland 1542, New Zealand Tel +64 21592064 Fax +61280808181

Email kannan.subramaniam@viatris.com

\begin{abstract}
Noncommunicable diseases (NCDs) are responsible for $71 \%$ of all worldwide mortality each year, and have an exceptionally large impact in low- and middle-income countries (LMICs). However, there is often a lack of local data from these countries to inform practice and policy improvements. Generating locally contextualized evidence base for NCDs that can help identify gaps, aid decision-making and improve patient care in LMICs needs an innovative approach. The approach used in Mapping the Patient Journey Towards Actionable Beyond the Pill Solutions (MAPS) is designed to quantitatively map different stages of the patient journey in four critical NCDs, ie, hypertension, dyslipidemia, depression, and pain (chronic and neuropathic) across selected LMICs in Africa, the Middle East, South East Asia, and Latin America. The key touchpoints along the patient journey include awareness, screening, diagnosis, treatment, adherence, and control or remission. MAPS employs an evidence mapping methodology that follows a three-step semisystematic review: 1) systematic peer-reviewed database search; 2) unstructured searches of local or real-world data; and 3) expert opinion. Evidence generation and visualization is based on locally validated and deduplicated data published over the last 10 years. This approach will be the first to provide quantitative mapping of the different stages of the patient journey for selected NCDs in LMICs. By focusing on local, patient-centric data, the goal of the MAPS initiative is to address and prioritize local research and knowledge gaps, then contribute to evidence-based, high-quality, and affordable advances in the management of NCDs in LMICs. This will ultimately improve patient outcomes and contribute towards the achievement of global NCD targets.
\end{abstract}

Keywords: noncommunicable diseases, low- and middle-income countries, decision-making, patient journey, evidence mapping

\section{Introduction}

Noncommunicable disease (NCD) is a collective term for a number of non-infectious diseases, including cardiovascular disease, cancer, diabetes, chronic respiratory disease, mental health problems and neurological disorders, and other chronic conditions. Together, NCDs are responsible for $71 \%$ of all worldwide mortality each year, ${ }^{1}$ and $44 \%$ of all NCD deaths are due to cardiovascular disease. ${ }^{2}$ Over a third of all NCD deaths occur prematurely, between the ages of 30 and 69 years, and the majority $(85 \%)$ of these premature deaths occur in low- and middle-income countries (LMICs). ${ }^{1}$ Premature mortality in LMICs results in cumulative economic losses of US\$7 trillion and contributes to the vicious cycle of poverty and inequity in these countries. ${ }^{3}$ 
Nearly two-thirds of all NCDs are linked to one or more shared risk factors, including tobacco use, unhealthy diet, physical inactivity, alcohol abuse, and air pollution. ${ }^{4}$ These can be addressed by strategies that include proper information provision and equitable access to effective healthcare. ${ }^{3}$ However, the lack of infrastructure, skilled human resources, and financial investment required to formulate effective policies and actions in LMICs make this problematic. ${ }^{5}$ These challenges highlight an urgent need for specific data to inform country- or region-specific approaches to ensure optimal local and context-specific management of NCDs.

The World Health Organization (WHO) has developed a framework on people-centered health that shifts the focus from diseases to place the needs of people at the center of health systems. ${ }^{6}$ To achieve this, there is a requirement for patient-centric approaches that shift the focus from disease to what is needed along the patient journey, from the prevention of risk factors to the control of established illness. Patients with NCDs often have a non-linear journey through the health system, changing with new test results, comorbidity diagnosis or symptoms. ${ }^{7}$ This journey reflects a continuum of care that includes an ongoing sequence of healthcare interactions. ${ }^{8}$ As reported recently, the patient journey for NCDs can be classified into five broad touchpoints: awareness, screening, diagnosis, treatment, and adherence, with integration of palliative care along the care continuum pathway. ${ }^{8}$ Several studies in LMICs examined prevalence, awareness, treatment and control as the key epidemiological touchpoints for monitoring the gaps in hypertension and diabetes management practices. $^{9-11}$ Based on these reports, patient journeys for those with NCDs include gaining an awareness of the disease process and associated risk factors, screening for the disease, its risk factors or comorbidities, diagnosis, treatment, adherence to the prescribed treatment, and control or remission of the disease (Figure 1). In the real world, patients may not necessarily follow the touchpoints sequentially, rather entering or exiting at any stage and may often need support and care at other points. ${ }^{8}$ These touchpoints are well researched and documented in developed countries but remain less evaluated in LMICs. This can result in the use of global data to inform local healthcare, which might not be accurate or appropriate. In contrast, reliable and accurate local evidence helps to identify relevant problems, inform the modification of international evidence, and facilitate the development of locally relevant and feasible solutions. Locally generated health policy systems research evidence has successfully demonstrated design and

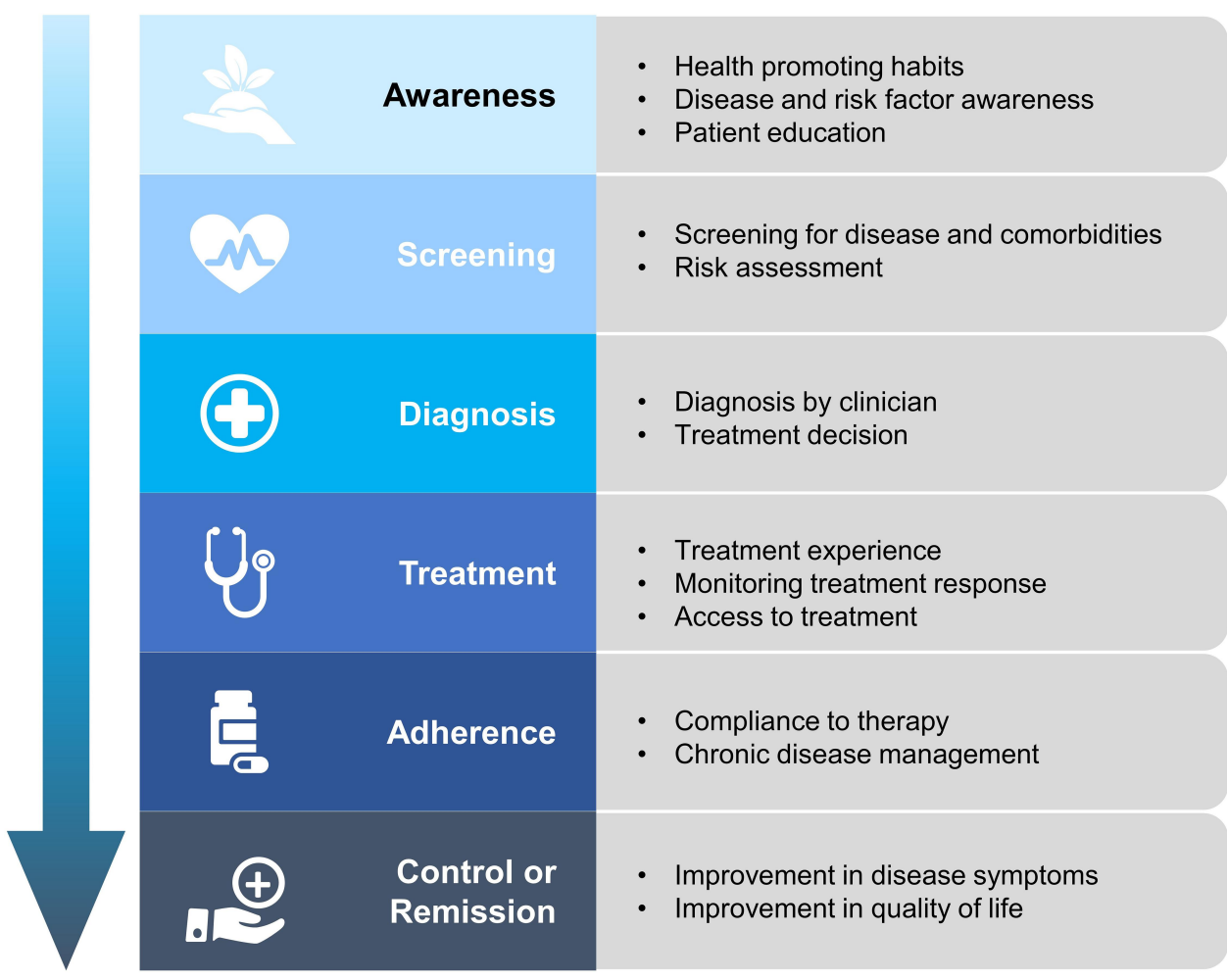

Figure I Stages of the patient journey in noncommunicable diseases. 
implementation of programs and policies to strengthen health systems in Mexico's Seguro Popular health insurance scheme and Thailand's national Universal Health Coverage programme. $^{12}$ Successful implementation of evidencebased policy requires not only the evidence of effectiveness of healthcare interventions, but also their cost-effectiveness, cultural appropriateness and effects on health inequalities. ${ }^{13}$ Similarly, the path from evidence generation to practice improvements follows multiple steps constituting knowledge of local care pathways, the clinical context and the institutional and political setting, and the patients' circumstances. $^{14}$

Given the difficulties in generating and obtaining reliable NCD data in LMICs, an innovative approach is required. "Evidence mapping" is a methodology for reviewing evidence to identify gaps or future research needs. ${ }^{15,16} \mathrm{It}$ differs from conventional systematic approaches in that it combines a systematic process with visual depiction of results to present vast amounts of data in a user-friendly, accessible, digestible and useable format. ${ }^{15}$ Evidence mapping relies on systematically searching evidence sources, documenting decisions on article inclusion/exclusion, and objective assessment of review scope. These characteristics can lead to a standardized protocol, which can be applicable across multiple NCD settings. ${ }^{17}$ The evidence mapping approach, which includes appraisal of data by local experts to validate the evidence and address data gaps, can help with strategies for evidence-informed decision-making (EDIM). EDIM has been defined as the intentional and systematic processes of bringing the best available scientific evidence on specific questions together with other relevant information to help weigh options and inform decisions that will affect priorities, policies, programs, and practices.

18 Overall, this research strategy, which combines systematic searching with other approaches for identifying evidence, fulfils the criteria of a semi-systematic review. ${ }^{19,20}$ The process allows the identification and analysis of all potentially relevant data on a given topic while using a transparent research approach that facilitates judgments about whether the data are rational and their usage appropriate. $^{19}$

Mapping the Patient Journey Towards Actionable Beyond the Pill Solutions (MAPS) is an initiative to facilitate a patient-centric approach to improving healthcare outcomes in the context of NCDs in LMICs. The main objective is to quantitatively map the different stages of the patient journey in key NCDs across selected LMICs. A secondary aim is to generate a framework to prioritize actionable gaps in the patient journey for those NCDs and propose strategic recommendations for "beyond-the-pill" solutions that will benefit patients and support decisionmaking. This paper presents the methodology for generating the evidence map of patient journeys for NCDs in LMICs.

\section{Description of MAPS Study Design}

The first phase of the MAPS initiative will focus on four NCDs: hypertension, dyslipidemia, depression (major depressive disorder), and pain (chronic and neuropathic). The selected NCDs represent the leading contributors of deaths and disability worldwide and in LMICs. ${ }^{21-23}$ Cardiovascular diseases have been identified as the leading cause of NCD-related mortality worldwide, accounting for 17.8 million deaths, based on estimates from the WHO and the Global Burden of Disease Study 2017. ${ }^{1,24}$ Hypertension is the leading driver of cardiovascular diseases and the leading risk factor for mortality. ${ }^{25}$ Raised blood pressure accounting for 10.4 million deaths and 218 million disability adjusted life-years (DALYs), in 2017, was the leading metabolic risk factor for cardiovascular disease burden globally. ${ }^{22}$ It is estimated that by 2025 , over $75 \%$ of world's hypertensive population will reside in LMICs. ${ }^{26}$ Raised total cholesterol, accounting for 4.4 million deaths and 93.8 million DALYs in 2016, was also an important metabolic risk factor for global cardiovascular disease burden. ${ }^{27}$ In terms of measuring the impact of NCDs on individuals, communities and health services, years lived with disability (YLDs) present the prevalence and severity of the disease. In 2017, chronic low back pain (65 million YLDs) was the leading cause of YLDs, followed by headache (54 million YLDs) and depressive disorders (43 million YLDs). ${ }^{21}$ Pain disorders - low back pain and headache-and depressive disorder have been the prevailing cause of non-fatal disability for over three decades. ${ }^{21}$ LMICs from Africa and the Middle East (AFME; Algeria, Egypt, Saudi Arabia, South Africa, and the United Arab Emirates), South East Asia (Malaysia, Philippines, Thailand, and Vietnam), and Latin America (LATAM; Argentina, Brazil, and Mexico) will be studied. Stages included in the patient journey are awareness, screening, diagnosis, treatment, adherence, and control or remission. An evidence mapping methodology will be employed which will follow a semi-systematic review of three sources of evidence: 1) systematic peer-reviewed database search; 2) unstructured searches of local or real-world data; and 3) expert opinion. The evidence mapping process will start with a systematic data review where possible. However, if there is a lack of data in some areas, the search 
strategy and evidence sources will be adjusted to ensure the availability of sufficient relevant information for meaningful analysis. The overall process for collecting and analyzing the data is illustrated in Figure 2.

\section{Sources of Evidence}

\section{Systematic Peer-Reviewed Database}

\section{Search}

Structured searches will be conducted across three electronic databases (Embase, MEDLINE, and BIOSIS) for records published in the English language over the previous 10 years. The 10 -year time period has been chosen because it provides a balance between availability, currency, and relevance of data from LMICs. Search strings for the four included NCDs with the appropriate disease $\mathrm{MeSH}$ terms, and their synonyms, patient journey stages, and LMIC regions will be queried (Table S1).

\section{Inclusion and Exclusion Criteria}

Studies identified from the systematic database search will be included in the analysis if they meet the following criteria:

- A systematic review and/or metanalysis, randomized controlled study, observational study (including casecontrol, cohort, cross-sectional, longitudinal, retrospective chart review, survey study types), narrative reviews (both full articles and conference abstracts)

- Human data from adult populations aged $\geq 18$ years

- Patient populations with hypertension, hypercholesterolemia, depression, or pain (chronic or neuropathic):

○ Hypertension is defined as average (SBP) $\geq 140$ $\mathrm{mmHg}$ and/or average diastolic blood pressure (DBP) $\geq 90 \mathrm{mmHg}^{28}$

- Hypercholesterolemia is defined as total cholesterol (TC) level $\geq 5.0 \mathrm{mmol} / \mathrm{L}$ or $\geq 200.0 \mathrm{mg} / \mathrm{dL}^{29-32}$
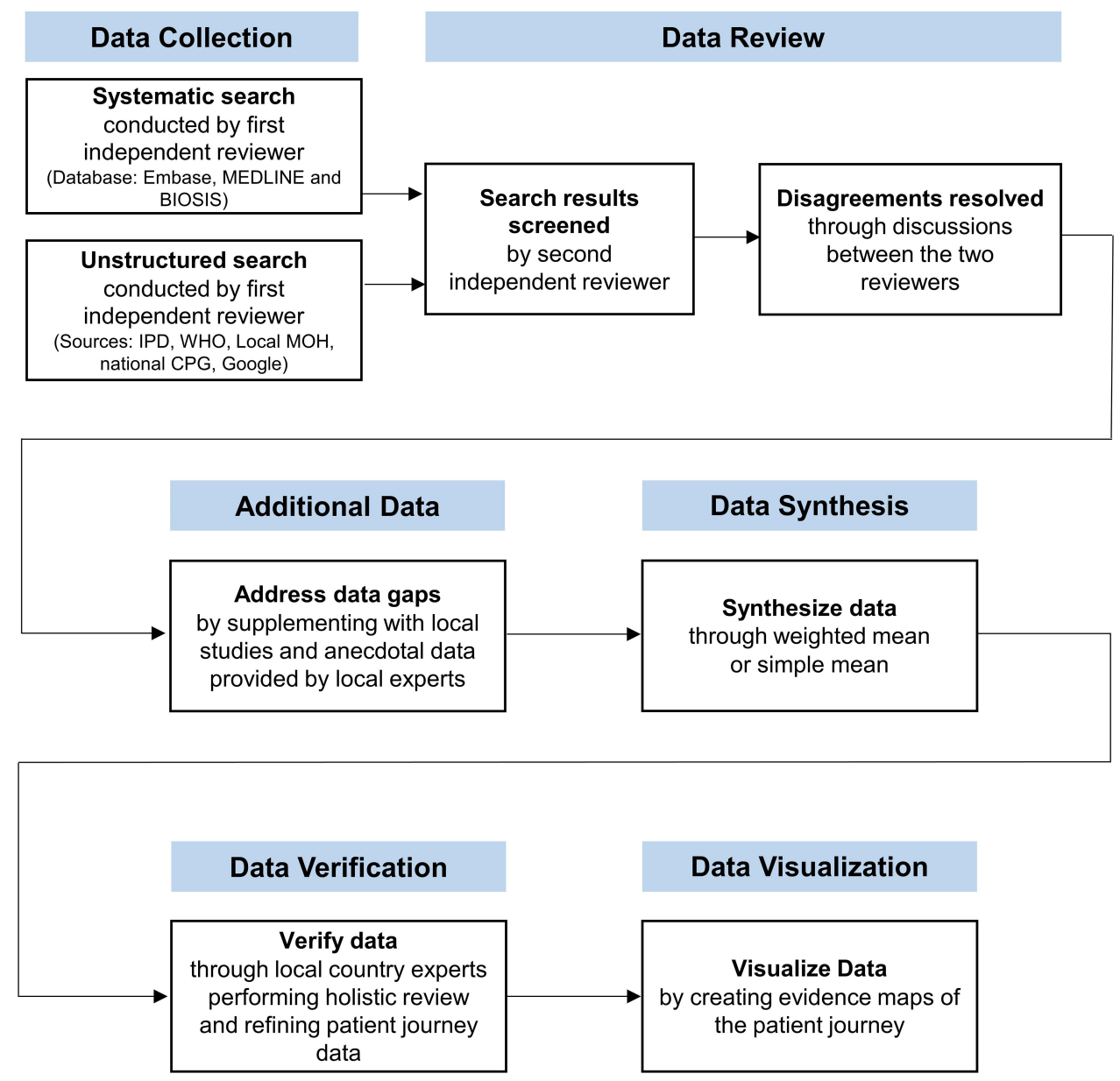

Figure 2 Overall process for data collection and analysis in the MAPS methodology.

Abbreviations: CPG, clinical practice and treatment guidelines; IPD, Incidence and Prevalence Database; MAPS, Mapping the Patient Journey Towards Actionable Beyond the Pill Solutions; MOH, Ministry of Health; WHO, World Health Organization. 
- Depression is defined according to the criteria common to the Diagnostic and Statistical Manual (DSM)-III, ${ }^{33}$ DSM-IV,${ }^{34}$ and DSM-V: ${ }^{35}$ the presence of $\geq 5$ symptoms in the last 2 weeks with $>1$ symptom being either depressed mood or the loss of interest or pleasure

- Chronic pain is defined as pain lasting $>3$ months, ${ }^{36}$ including osteoarthritis and low back pain

- Neuropathic pain is defined as pain due to lesion or disease of the somatosensory system, ${ }^{37,38}$ including diabetic peripheral neuropathy and low back pain with a neuropathic component

- Reporting quantitative epidemiological data for each stage of the patient journey (awareness, screening, diagnosis, treatment, adherence, and control or remission) in hypertension, ${ }^{9}$ dyslipidemia, ${ }^{39}$ depression, ${ }^{40}$ and pain $^{41}$ (chronic and neuropathic) (Table 1)

- Data from selected LMICs.
Studies published before 2010, non-English language publications, case studies, letters to the editor, editorials, studies including specific patient subgroups (eg, those with comorbidities, pregnant women, etc), and duplicate records will be excluded.

\section{Unstructured Search}

To address any gaps in systematic searches (particularly relating to specific local data), structured searches will be supplemented by searching the Incidence and Prevalence Database (IPD), the WHO website, National Ministry of Health websites for the relevant countries, national clinical practice and treatment guidelines, and Google (the Google search will include a combination of the key MeSH terms from the systematic literature search). There will be no date limits on material identified in the unstructured searches.

Table I Definitions for Patient Journey Relating to Four Key Noncommunicable Diseases

\begin{tabular}{|c|c|c|c|c|}
\hline & Hypertension & Dyslipidemia & Depression & $\begin{array}{l}\text { Pain (Chronic and } \\
\text { Neuropathic) }\end{array}$ \\
\hline $\begin{array}{l}\text { Awareness of } \\
\text { disease process }\end{array}$ & $\begin{array}{l}\text { Self-reported awareness, } \\
\text { or any prior diagnosis, of } \\
\text { HTN by an HCP }\end{array}$ & $\begin{array}{l}\text { Self-reported awareness, or } \\
\text { any prior diagnosis, of high } \\
\text { serum total cholesterol } \\
\text { level by an HCP }\end{array}$ & $\begin{array}{l}\text { Self-reported knowledge or } \\
\text { awareness of depression/ } \\
\text { depressive disorders }\end{array}$ & $\begin{array}{l}\text { Self-reported knowledge or } \\
\text { awareness of chronic pain or } \\
\text { neuropathic pain }\end{array}$ \\
\hline $\begin{array}{l}\text { Screening for } \\
\text { disease or risk } \\
\text { factors, including } \\
\text { surrogate } \\
\text { markers }\end{array}$ & $\begin{array}{l}\text { Measurement of BP by } \\
\text { a doctor or other health } \\
\text { worker }\end{array}$ & $\begin{array}{l}\text { Cholesterol levels } \\
\text { measured by a doctor or } \\
\text { other health worker }\end{array}$ & $\begin{array}{l}\text { Use of assessment } \\
\text { questionnaires to screen for } \\
\text { depression/depressive } \\
\text { symptoms/depressive } \\
\text { disorders }\end{array}$ & $\begin{array}{l}\text { Use of standard pain assessment } \\
\text { tools or neurological } \\
\text { examination }\end{array}$ \\
\hline Diagnosis & $\begin{array}{l}\text { Diagnosis of HTN by an } \\
\mathrm{HCP}\end{array}$ & $\begin{array}{l}\text { Diagnosis of hyper- } \\
\text { cholesterolemia by an HCP }\end{array}$ & $\begin{array}{l}\text { Diagnosis of depression/ } \\
\text { depressive disorder by an } \\
\text { HCP }\end{array}$ & $\begin{array}{l}\text { Diagnosis with any type of } \\
\text { chronic or neuropathic pain }\end{array}$ \\
\hline Treatment & $\begin{array}{l}\text { Use of antihypertensive } \\
\text { medication for the } \\
\text { management of high BP }\end{array}$ & $\begin{array}{l}\text { Use of medications to } \\
\text { reduce high cholesterol } \\
\text { levels }\end{array}$ & $\begin{array}{l}\text { Use of pharmacotherapy or } \\
\text { psychotherapy to treat } \\
\text { depression/depressive } \\
\text { disorders }\end{array}$ & $\begin{array}{l}\text { Use of pharmacological pain } \\
\text { medication }\end{array}$ \\
\hline $\begin{array}{l}\text { Adherence to } \\
\text { treatment advised } \\
\text { by attending } \\
\text { physician }\end{array}$ & $\begin{array}{l}\text { Self-reported adherence } \\
\text { and/or compliance with } \\
\text { prescribed } \\
\text { antihypertensive } \\
\text { medication }\end{array}$ & $\begin{array}{l}\text { Self-reported adherence } \\
\text { and/or compliance with } \\
\text { prescribed cholesterol- } \\
\text { lowering medication }\end{array}$ & $\begin{array}{l}\text { Self-reported adherence and/ } \\
\text { or compliance with } \\
\text { prescribed pharmacotherapy } \\
\text { or psychotherapy }\end{array}$ & $\begin{array}{l}\text { Self-reported adherence and/or } \\
\text { compliance with prescribed } \\
\text { pharmacological pain medication }\end{array}$ \\
\hline $\begin{array}{l}\text { Control or } \\
\text { remission of } \\
\text { disease }\end{array}$ & $\begin{array}{l}\text { Target } \mathrm{BP} \leq 140 / 90 \\
\mathrm{mmHg} \text { during treatment }\end{array}$ & $\begin{array}{l}\text { Target total cholesterol } \\
\text { level } \leq 5.0 \mathrm{mmol} / \mathrm{L} \text { or } \\
\leq 200 \mathrm{mg} / \mathrm{dL} \text { during } \\
\text { treatment }\end{array}$ & $\begin{array}{l}\text { Improvement in depressive } \\
\text { symptoms during treatment }\end{array}$ & $\begin{array}{l}\text { Improvement in pain symptoms, } \\
\text { quality of life or disease } \\
\text { symptoms (self-reported or } \\
\text { using an assessment tool) }\end{array}$ \\
\hline
\end{tabular}

Abbreviations: BP, blood pressure; HCP, healthcare professional; HTN, hypertension. 


\section{Expert Opinion}

Any data gaps identified in the patient journey following the systematic and unstructured searches will be addressed through studies published in local languages and/or anecdotal data sought from local experts in the four NCD areas contacted via face-to-face meetings or telephonic discussions. These local experts will be national or leading health specialists in each disease area (for example, leaders of local medical associations, academic consultants in leading hospitals, or leaders of national Ministry of Health projects) who also fulfill pre-specified selection criteria: 1) academic and vocational qualifications in the specialty to be reviewed; 2) research interest and achievement in their field of specialty; 3) authors of relevant articles published in peer-reviewed journals; 4) members of a relevant national professional society; and 5) recognized as leaders by their peers. The goal will be to have 1-3 experts from each country.

An Ethics Board approval will be sought, as applicable, at the time of data collection from local experts.

\section{Data Synthesis, Verification, and Analysis}

Systematic and unstructured searches will be conducted by an independent reviewer, and the title and abstract of each article will be sequentially screened against the inclusion and exclusion criteria. The results of these searches (including general information about the article, including the title, article citation, author names, year of publication, abstract, study design, study participants, and study setting) will be reviewed by a second independent reviewer who will exclude non-relevant studies; any disagreements will be resolved through discussion between the two reviewers. In order to detect large effect, as expected for the patient journey stages, large sample size would not be needed and a nationally representative population sample size of 500 will be considered adequate for this analysis. ${ }^{42}$ Where nationally representative populations from studies with a sample size of $\geq 500$ are not available, data points from studies that include only a population sub-group, single-center experience, or sample size of $<500$ will be eligible for inclusion. Hierarchy of evidence recognizes higher ranking of evidence coming from studies that are multicenter and with multiple populations, settings, and circumstances. $^{43}$

When information from adequately powered studies is not available, combined data from the systematic and unstructured searches, local sources and expert opinion will then be used to synthesize data for each patient journey touchpoint across each NCD using appropriate measures of central tendency (point estimates of weighted mean or simple average) to minimize bias arising from the methodological limitations of different studies. The resulting dataset will be exported into a Microsoft Excel document, and quantitative data will be categorized according to the NCD, country, and step in the patient journey. The data will then be verified by $\geq 1$ local expert to ensure consistency with real-world insights and expert opinion. Additionally, the study design of shortlisted studies will be appraised to assign corresponding level of evidence based on the levels developed by the Centre for Evidence Based Medicine. ${ }^{44,45}$ The synthesized evidence or lack thereof will be depicted visually as evidence maps or gaps for each of the four NCDs in each of the 12 LMICs being studied to provide an overview of the unmet needs along the patient journey and identify areas where there is an evidence gap due to a lack of local, reliable, and goodquality data.

\section{Data Visualization}

An important element of evidence mapping is exploration and mapping of evidence through data visualization. ${ }^{15}$ The point estimates from each patient journey component will be visualized as doughnut charts depicted in different colors to highlight the gaps quantitatively in each patient journey stage (Figure 3). Further, the point estimates will be extrapolated to data at the national level to estimate disease burden as the absolute number of patients at-risk (prevalence), remaining undiagnosed, being untreated and uncontrolled for their conditions in the respective LMICs, sequentially along the patient journey and presented as a funnel diagram (Figure 4). An evidence map of NCD patient journey for each condition across each LMIC will be presented as a bubble plot (Figure 5), where the coordinates of each bubble correspond to a specific touchpoint and the number of supporting evidence sources and the size of the bubble corresponds to the estimated effect size of the touchpoint.

\section{Discussion}

In this paper, we describe a novel approach to identifying and verifying local country data for four NCDs and chronic conditions in selected LMICs. The subsequent analyses will be the first to provide a quantitative mapping of local information along the different stages of the 

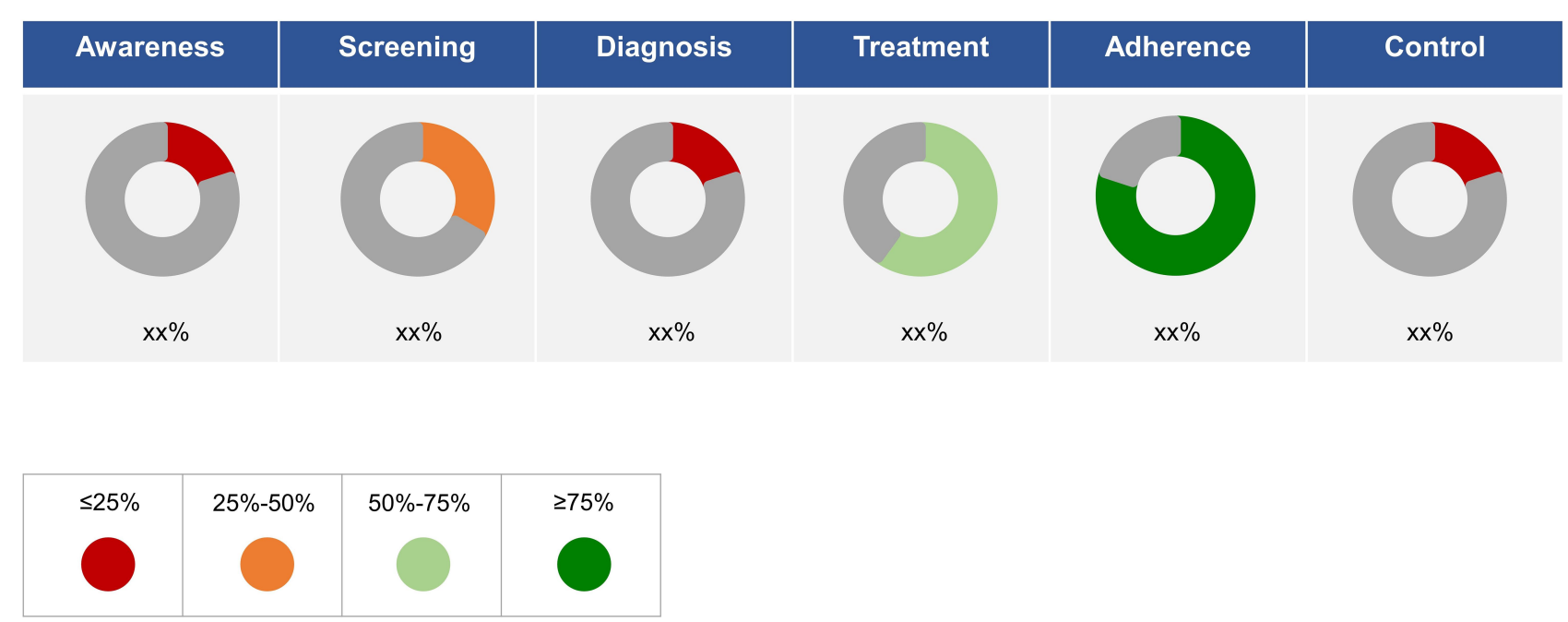

Figure 3 Visualization of the point estimates of patient journey stages.

At Risk Population Number (in million)

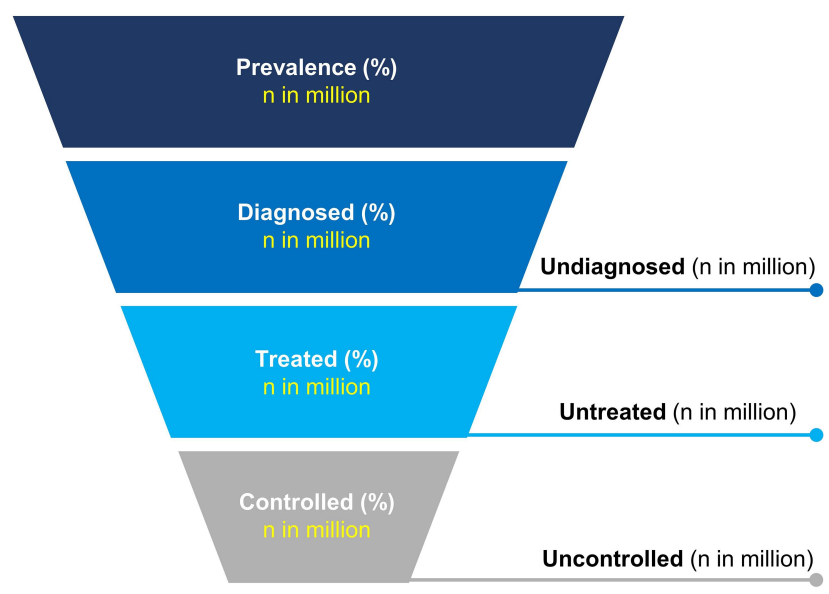

Figure 4 Estimating the proportion and absolute numbers of at-risk population sequentially through patient journey stages. $n=$ absolute number of at-risk populations extrapolated from proportion of patients estimated at various patient journey stages.

patient journey for these conditions. Understanding patient journey data in this manner has benefits for all stakeholders. The information will support healthcare professionals to better appreciate the patient's perspective and bridge gaps in clinical practice. ${ }^{46}$ Policymakers and health system managers can utilize the data to review and address deficiencies in health policy; and inform resource allocation, healthcare workforce, capability development and integration of NCD care, and improve efficiencies. ${ }^{47}$ Patients stand to gain from these improvements with paths to greater health literacy and processes that enable greater participation in managing their health. ${ }^{48}$ The gaps in the mapped evidence can be transformed into beyond- the-pill solutions by bringing together traditional and nontraditional stakeholders for NCD management. The MAPS process will thus deliver an opportunity to use relevant local information rather than the need to extrapolate generic international data. This is the rationale for the study.

Although it is widely recognized that NCDs are a significant issue for development and sustainability in LMICs, ${ }^{1,3}$ programs to reduce the burden of NCDs have been limited by a lack of specific information on the design and implementation of these initiatives, and on their long-term impact. ${ }^{49}$ There are other systemic, social, and financial barriers in LMICs that retard the translation of evidence into policy and practice improvements. ${ }^{13}$ Strengthening local research capacity is essential, as noted in the WHO Global Action Plan for the Prevention and Control of NCDs 2013-2020. ${ }^{3}$ This is a critical way to help LMICs to reach global NCD targets by $2025 .^{50}$ Resilient and responsive health systems require decision makers and health actors to identify, collect, and interpret local evidence while responding to new or emerging healthcare challenges, and monitor periodically. ${ }^{47}$ By focusing on local, patient-centric data, the goal of the MAPS initiative is to address and prioritize research and knowledge gaps, then provide support and recommendations to improve patient care and decision-making to effectively tackle NCDs in LMICs.

True systematic reviews may not always be feasible for informing pressing public health issues and decisions. Policy decisions must be informed from a broad knowledge base from scientific evidence, grey literature and tacit knowledge of local healthcare professionals for 


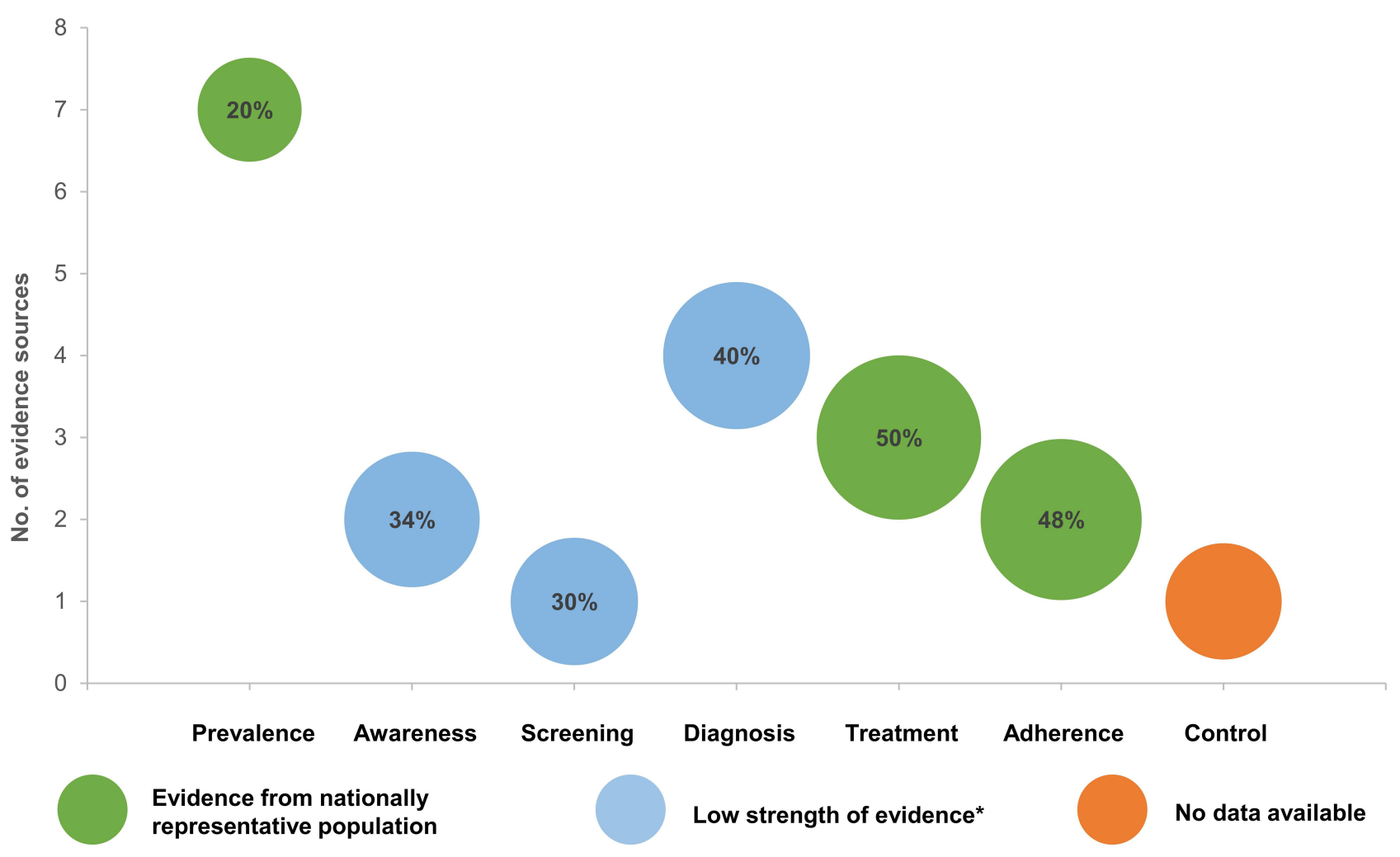

Figure 5 Sample evidence map of noncommunicable disease patient journey. *Low strength of evidence (anecdotal data and studies with non-nationally representative population, single center or sample size<500).

contextualized evidence. ${ }^{51}$ The semi-systematic review has been identified as a good strategy for mapping theoretical approaches or themes, and for identifying knowledge gaps within the literature. ${ }^{19}$ An important limitation for MAPS in its current iteration is the absolute lack of data from LMICs in some areas. Therefore, the semi-systematic approach is being used to ensure that as much relevant data as possible are included and to minimize data gaps given the high importance of NCDs in LMICs. However, the lack of patient registries and infrastructure, and a segmented approach to care in some LMICs makes this problematic. ${ }^{52}$ Also, it highlights the importance of the MAPS process to address these gaps. Accurate local data will allow recommendations based on international evidence to be tailored for different countries, providing a targeted and practical approach to patient management. Local evaluation activities have the most influence on public health decision-making as they meet the requirements of locality of evidence, and thereby transferability of evidence. ${ }^{53}$ The value of experiential knowledge and opinions of local experts in public health decision-making is highlighted by their frequent utilization along with other robust forms of evidence including national guidelines and systematic reviews and meta-analysis, even in developed countries. ${ }^{53-55}$ A similar semi-systematic approach based on a combination of literature review, expert opinion, and stakeholder feedback has been used to inform the development of public health intervention research on novel psychoactive substances in the United Kingdom. ${ }^{56}$ The lack of specific data in that field is comparable to the issues relating to NCDs in LMICs, highlighting the usefulness of the semi-systematic approach in these settings. There is evidence that employing supplementary search techniques, such as unstructured/citation searches, grey literature searches and contact with experts, in combination with systematic searches identified a greater proportion of higher quality articles in the psychiatry and social sciences fields with poorly defined concepts/themes and variability in indexing. ${ }^{57}$

NCDs include a number of common conditions, including cardiovascular diseases, cancer, diabetes, chronic respiratory diseases, and mental health and neurological disorders. ${ }^{58}$ The areas of focus for the current analyses are cardiovascular disease (hypertension and dyslipidemia), chronic pain, and depression. The prevalence, diagnostic criteria, and treatment guidelines for these NCDs will vary 
between LMICs. For example, low-density lipoprotein cholesterol (LDL-C) is considered a more sensitive marker for determination of atherosclerotic cardiovascular disease risk, though in most LMICs total cholesterol tests are preferred due to their low cost and availability. ${ }^{59,60}$ For ease of data collection, commonly recognized definitions and classifications, as outlined in international guidelines, will be used in the MAPS approach. In addition, we considered pharmacotherapy as a measure of treatment in NCD patients. However, the treatment of NCDs such as hypertension frequently involves the use of medication along with lifestyle modifications targeting the major modifiable risk factors (in the case of hypertension, these include salt intake, unhealthy diet, excessive alcohol consumption, smoking, physical inactivity, stress, and air pollution). ${ }^{61}$ We felt that it was important to make a start on providing essential local data in LMICs, despite limiting the analysis to specific conditions and parameters. Additional research investigating diabetes, cancer, and chronic respiratory diseases will be required to obtain a comprehensive picture of the four key groups of NCDs in LMICs. Our evidence mapping exercise could potentially serve as a roadmap for future collaborations to generate evidence on other factors playing a role in the NCD patient journey that are not included in the current analyses.

The importance and relevance of including both cardiovascular disease and mental health issues in the initial MAPS analysis have been emphasized by the coronavirus disease (COVID-19) pandemic. Along with those aged over 65 years, ${ }^{62-64}$ patients with NCDs such as cardiovascular disease (and diabetes or respiratory disease) are at substantially higher risk of becoming severely ill or dying if they become infected with the SARS-CoV-2 virus. ${ }^{64}$ Furthermore, the impact of mental health issues associated with challenges such as enforced isolation and the financial impact of the pandemic for an extended period of time will likely outlast the virus in the community, highlighting the need for both urgent and ongoing mental health strategies. $^{65}$ The strain placed on healthcare services by the need to care for large numbers of COVID-19 patients and the requirement for physical distancing has meant that services for the prevention and treatment of NCDs have been substantially disrupted in many countries, which could result in a long-term increase in NCD-related morbidity and mortality. ${ }^{66}$ This is likely to disproportionately affect LMICs, where there are high rates of COVID-19 and also less robust healthcare systems, and therefore highlights the importance of approaches designed to improve future management of NCDs in these countries.

A key strength of this study design is the use of a semisystematic approach to ensure maximum coverage of data in the patient journey. Local applicability will be maximized by the validation of data by local experts. ${ }^{53-55}$ However, several limitations will be unavoidable. These include the risk of several forms of bias, ${ }^{67}$ such as from a lack of quality assessment, ${ }^{68}$ and the possibility of publication bias (although the semi-systematic approach should limit this). The exclusion of non-clinical study types, such as case reports and letters to the editor, means that data published in these formats will not be captured in the analysis. Inclusion of only English language studies results in a language bias that is relatively common in systematic reviews, ${ }^{69}$ but this should be minimized by an attempt to include local language studies during the data validation step by local experts. Another potential limitation of this study could be the lack of a standardized questionnaire for data verification. There may also be limitations around the concepts used in specific disease areas, such as the focus on pharmacological treatment for hypertension and the use of total cholesterol levels to define hypercholesterolemia. These will be investigated and discussed in more detail during the data analysis phase of the study. It is also important to note that evidence maps describe the state of the evidence at a specific point in time, and therefore need to be updated regularly to reflect the latest practice; this should take place at least every 3 years, but annually may be preferable in rapidly evolving areas. ${ }^{16}$

Implementation of NCD policies change over time, ${ }^{70}$ and this may impact on indices that are measured. Therefore, an analysis including MAPS needs to be refreshed periodically to consider longitudinal time trends in data.

\section{Conclusion}

The burden of NCDs comes with a high human and economic cost, especially in LMICs. Patient journey data generated by the proposed study will represent the first comprehensive analysis from these regions. The goal is that a better understanding of the patient journey and specific local data will contribute to evidence-based, highquality, and affordable advances in the management of NCDs. When applied at touchpoints along the patient journey, "beyond-the-pill" solutions can improve awareness to engage patients better, and to predict and prevent 
risk factors that lead to adverse health consequences. MAPS will permit a clearer understanding of patient journeys and allow better integration of patients into the healthcare system as decision makers, thus navigating the system with more confidence and achieving better outcomes.

\section{Acknowledgments}

Editorial and medical writing support were provided by Nicola Ryan, an independent medical writer, funded by Pfizer.

\section{Disclosure}

No author received an honorarium for the preparation of the article. Pai-Hui Huang, Barrett Jeffers and Kannan Subramaniam are current employees of Viatris Inc and were previously employed at Upjohn Division, Pfizer Ltd. Tanaya Bharatan and Kaveri Sidhu are employees of Pfizer Ltd. Dr. Peter Lansberg has received consultancy and speaker honorarium payments from Pfizer, Amgen, and Sanofi. The remaining authors have no conflicts of interest to declare. The views and opinions expressed in this article are those of the authors. They do not represent or reflect in any way the official policy or position of their current or previous employers. The authors report no other conflicts of interest in this work.

\section{References}

1. World Health Organization. Noncommunicable diseases. Available from: https://www.who.int/news-room/fact-sheets/detail/noncommunic able-diseases. Accessed June 15, 2020.

2. World Health Organization. Noncommunicable diseases country profiles; 2018. Available from:https://www.who.int/publications/i/ item/9789241514620. Accessed June, 2020.

3. World Health Organization. Global action plan for the prevention and control of NCDs 2013-2020. Available from: https://apps.who.int/iris/ bitstream/handle/10665/94384/9789241506236_eng.pdf?sequence=1. Accessed June 10, 2020.

4. NCD Alliance. Home page. Available from: https://ncdalliance.org. Accessed June 29, 2020.

5. Tripathy JP. Research priorities in non-communicable diseases in developing countries: time to go beyond prevalence studies. Public Health Action. 2018;8(2):98-99. doi:10.5588/pha.18.0023

6. World Health Organization. WHO Framework on integrated people-centered health services. Available from: https://www.who.int/ servicedeliverysafety/areas/people-centred-care/en/. Accessed June 20, 2020.

7. Patient experience; 2020. Available from: https://www.elsevier.com/clin ical-solutions/nurses/patient-experience. Accessed October 9, 2020.

8. Devi R, Kanitkar K, Narendhar R, Sehmi K, Subramaniam K. A narrative review of the patient journey through the lens of non-communicable diseases in low- and middle-income countries. Adv Ther. 2020;37:4808-4830. doi:10.1007/s12325-020-01519-3
9. Chow CK, Teo KK, Rangarajan S, et al. Prevalence, awareness, treatment, and control of hypertension in rural and urban communities in high-, middle-, and low-income countries. JAMA. 2013;310 (9):959-968. doi:10.1001/jama.2013.184182

10. Irazola V, Rubinstein A, Bazzano L, et al. Prevalence, awareness, treatment and control of diabetes and impaired fasting glucose in the Southern Cone of Latin America. PLoS One. 2017;12(9):e0183953. doi:10.1371/journal.pone.0183953

11. Li M-Z, Su L, Liang B-Y, et al. Trends in prevalence, awareness, treatment, and control of diabetes mellitus in Mainland China from 1979 to 2012. Int J Endocrinol. 2013;2013:753150. doi:10.1155/ 2013/753150

12. Shroff ZC, Javadi D, Gilson L, Kang R, Ghaffar A. Institutional capacity to generate and use evidence in LMICs: current state and opportunities for HPSR. Health Res Policy Syst. 2017;15(1):94. doi:10.1186/s12961-017-0261-1

13. Haines A, Kuruvilla S, Borchert M. Bridging the implementation gap between knowledge and action for health. Bull World Health Organ. 2004;82(10):724-731; discussion 732.

14. Haynes B, Haines A. Barriers and bridges to evidence based clinical practice. BMJ. 1998;317(7153):273-276. doi:10.1136/bmj.317.71 53.273

15. Miake-Lye IM, Hempel S, Shanman R, Shekelle PG. What is an evidence map? A systematic review of published evidence maps and their definitions, methods, and products. Syst Rev. 2016;5:28. doi:10.1186/s13643-016-0204-x

16. Saran A, White H. Evidence and gap maps: a comparison of different approaches. Campbell Syst Rev. 2018;14(1):1-38. doi:10.4073/ cmdp. 2018.2

17. O'Leary BC, Woodcock P, Kaiser MJ, Pullin AS. Evidence maps and evidence gaps: evidence review mapping as a method for collating and appraising evidence reviews to inform research and policy. Environ Evid. 2017;6(1):19. doi:10.1186/s13750-017-0096-9

18. Peirson L, Ciliska D, Dobbins M, Mowat D. Building capacity for evidence informed decision making in public health: a case study of organizational change. BMC Public Health. 2012;12:137. doi:10.1186/1471-2458-12-137

19. Snyder H. Literature review as a research methodology: an overview and guidelines. J Bus Res. 2019;104:333-339. doi:10.1016/j. jbusres.2019.07.039

20. Hunter AJ, Luck GW. Defining and measuring the social-ecological quality of urban greenspace: a semi-systematic review. Urban Ecosyst. 2015;18(4):1139-1163. doi:10.1007/s11252-015-0456-6

21. G. B. D. Disease Injury Incidence and Prevalence Collaborators. Global, regional, and national incidence, prevalence, and years lived with disability for 354 diseases and injuries for 195 countries and territories, 1990-2017: a systematic analysis for the Global Burden of Disease Study 2017. Lancet. 2018;392(10159):1789-1858.

22. G. B. D. Risk Factor Collaborators. Global, regional, and national comparative risk assessment of 84 behavioural, environmental and occupational, and metabolic risks or clusters of risks for 195 countries and territories, 1990-2017: a systematic analysis for the Global Burden of Disease Study 2017. Lancet. 2018;392(10159):1923-1994. doi:10.1016/S0140-6736(18)32225-6

23. World health Organization. Depression: key facts; 2020; Available from: https://www.who.int/news-room/fact-sheets/detail/depression. Accessed October 9, 2020.

24. G. B. D. Causes of Death Collaborators. Global, regional, and national age-sex-specific mortality for 282 causes of death in 195 countries and territories, 1980-2017: a systematic analysis for the Global Burden of Disease Study 2017. Lancet. 2018;392 (10159):1736-1788.

25. Sarki AM, Nduka CU, Stranges S, Kandala NB, Uthman OA. Prevalence of hypertension in low- and middle-income countries: a systematic review and meta-analysis. Medicine (Baltimore). 2015;94(50):e1959. doi:10.1097/MD.0000000000001959 
26. Kearney PM, Whelton M, Reynolds K, Muntner P, Whelton PK, He J. Global burden of hypertension: analysis of worldwide data. Lancet. 2005;365(9455):217-223. doi:10.1016/S0140-6736(05)17741-1

27. Gakidou E, Afshin A, Abajobir AA; G. B. D. Risk Factors Collaborators. Global, regional, and national comparative risk assessment of 84 behavioural, environmental and occupational, and metabolic risks or clusters of risks, 1990-2016: a systematic analysis for the Global Burden of Disease Study 2016. Lancet. 2017;390 (10100):1345-1422. doi:10.1016/S0140-6736(17)32366-8

28. Weber MA, Schiffrin EL, White WB, et al. Clinical practice guidelines for the management of hypertension in the community: a statement by the American Society of Hypertension and the International Society of Hypertension. $J$ Clin Hypertens (Greenwich). 2014;16(1):14-26. doi:10.1111/jch.12237

29. InformedHealth.org [Internet]. Cologne, Germany: Institute for Quality and Efficiency in Health Care (IQWiG); 2006. High cholesterol: overview; 2013. Available from: https://www.ncbi.nlm.nih.gov/ books/NBK279318/. Accessed July 14, 2020.

30. Non-communicable Disease Risk Factor Survey (STEPS). Data Book for UAE 2017-2018. Available from: https://www.mohap.gov.ae/en/ OpenData/Pages/default.aspx. Accessed July 17, 2020.

31. Mat Rifin H, Lourdes T, Majid N, et al. Hypercholesterolemia prevalence, awareness, treatment and control among adults in Malaysia: the 2015 National Health and Morbidity Survey, Malaysia. Glob J Health Sci. 2018;10:11. doi:10.5539/gjhs.v10n7p11

32. Rivas-Gomez B, Almeda-Valdés P, Tussié-Luna MT, Aguilar-Salinas CA. Dyslipidemia in Mexico, a call for action. Rev Invest Clin. 2018;70(5):211-216. doi:10.24875/RIC.18002573

33. American Psychiatric Association. Diagnostic and Statistical Manual of Mental Disorders. 3rd ed. Arlington, VA: American Psychiatric Publishing; 1980.

34. American Psychiatric Association. Diagnostic and Statistical Manual of Mental Disorders. 4th ed. Washington, DC: American Psychiatric Publishing; 2000.

35. American Psychiatric Association. Diagnostic and Statistical Manual of Mental Disorders. 5th ed. Arlington, VA: American Psychiatric Publishing; 2013.

36. Treede RD, Rief W, Barke A, et al. A classification of chronic pain for ICD-11. Pain. 2015;156(6):1003-1007. doi:10.1097/j. pain. 0000000000000160

37. International Association for the Study of Pain. IASP terminology. Neuropathic pain. Available from: https://www.iasp-pain.org/ Education/Content.aspx?ItemNumber=1698\#Neuropathicpain. Accessed July 14, 2020.

38. Jensen TS, Baron R, Haanpää M, et al. A new definition of neuropathic pain. Pain. 2011;152(10):2204-2205. doi:10.1016/j. pain.2011.06.017

39. Supiyev A, Nurgozhin T, Zhumadilov Z, Peasey A, Hubacek JA, Bobak M. Prevalence, awareness, treatment and control of dyslipidemia in older persons in urban and rural population in the Astana region, Kazakhstan. BMC Public Health. 2017;17(1):651. doi:10.1186/s12889-017-4629-5

40. Fujii RK, Goren A, Annunziata K, Mould-Quevedo J. Prevalence, awareness, treatment, and burden of major depressive disorder: estimates from the national health and wellness survey in Brazil. Value Health Reg Issues. 2012;1(2):235-243. doi:10.1016/j. vhri.2012.09.011

41. Goren A, Gross HJ, Fujii RK, Pandey A, Mould-Quevedo J. Prevalence of pain awareness, treatment, and associated health outcomes across different conditions in Brazil. Revista Dor. 2012;13:308-319. doi:10.1590/S1806-00132012000400002

42. Hajian-Tilaki K. Sample size estimation in epidemiologic studies. Caspian J Intern Med. 2011;2(4):289-298.

43. Evans D. Hierarchy of evidence: a framework for ranking evidence evaluating healthcare interventions. J Clin Nurs. 2003;12(1):77-84. doi:10.1046/j.1365-2702.2003.00662.x
44. OCEBM Levels of Evidence Working Group. The Oxford Levels of Evidence 2. 2011; Available from:https://www.cebm.ox.ac.uk/ resources/levels-of-evidence/ocebm-levels-of-evidence. Accessed December 11, 2020.

45. Howick J. Oxford centre for evidence-based medicine: levels of evidence (March 2009). 2009; Available from:https://www.cebm.ox. ac.uk/resources/levels-of-evidence/oxford-centre-for-evidence-basedmedicine-levels-of-evidence-march-2009. Accessed December 11, 2020.

46. Lall D, Engel N, Devadasan N, Horstman K, Criel B. Models of care for chronic conditions in low/middle-income countries: a 'best fit' framework synthesis. BMJ Global Health. 2018;3(6):e001077. doi:10.1136/bmjgh-2018-001077

47. Vanyoro KP, Hawkins K, Greenall M, Parry H, Keeru L. Local ownership of health policy and systems research in low-income and middle-income countries: a missing element in the uptake debate. $B M J$ Global Health. 2019;4(4):e001523. doi:10.1136/bmjgh-2019-001523

48. Lee YJ, Shin SJ, Wang RH, Lin KD, Lee YL, Wang YH. Pathways of empowerment perceptions, health literacy, self-efficacy, and self-care behaviors to glycemic control in patients with type 2 diabetes mellitus. Patient Educ Couns. 2016;99(2):287-294. doi:10.1016/j. pec.2015.08.021

49. Haregu TN, Byrnes A, Singh K, et al. A scoping review of non-communicable disease research capacity strengthening initiatives in low and middle-income countries. Global Health Res Policy. 2019;4(1):31. doi:10.1186/s41256-019-0123-1

50. World Health Organization. Noncommunicable diseases: campaign for action - meeting the NCD targets. Know the NCD targets. Available from: https://www.who.int/beat-ncds/take-action/targets/ en/. Accessed June 16, 2020.

51. Langlois EV, Becerril Montekio V, Young T, Song K, AlcaldeRabanal J, Tran N. Enhancing evidence informed policymaking in complex health systems: lessons from multi-site collaborative approaches. Health Res Policy Syst. 2016;14:20. doi:10.1186/ s12961-016-0089-0

52. Akhlaq A, Sheikh A, Pagliari C. Barriers and facilitators to health information exchange in low- and middle-income country settings: a systematic review protocol. J Innov Health Inform. 2015;22 (2):284-292. doi:10.14236/jhi.v22i2.98

53. Kneale D, Rojas-Garcia A, Raine R, Thomas J. The use of evidence in English local public health decision-making: a systematic scoping review. Implement Sci. 2017;12(1):53. doi:10.1186/s13012-017-0577-9

54. Titler M. The evidence for evidence-based practice implementation. In: Hughes R, editor. Patient Safety and Quality: An Evidence-Based Handbook for Nurses. Rockville (MD): Agency for Healthcare Research and Quality (US); 2008.

55. Orton L, Lloyd-Williams F, Taylor-Robinson D, O'Flaherty M, Capewell S, Ross JS. The use of research evidence in public health decision making processes: systematic review. PLoS One. 2011;6(7): e21704. doi:10.1371/journal.pone.0021704

56. Mdege ND, Meader N, Lloyd C, Parrott S, McCambridge J. The Novel Psychoactive Substances in the UK Project: Empirical and Conceptual Review Work to Produce Research Recommendations. Southampton (UK): NIHR Journals Library; 2017.

57. Papaioannou D, Sutton A, Carroll C, Booth A, Wong R. Literature searching for social science systematic reviews: consideration of a range of search techniques. Health Info Libr J. 2010;27 (2):114-122. doi:10.1111/j.1471-1842.2009.00863.x

58. NCD Alliance. NCDs. Available from: https://ncdalliance.org/whyncds/NCDs. Accessed June 16, 2020.

59. Grundy SM, Stone NJ, Bailey AL, et al. 2018 AHA/ACC/AACVPR/ AAPA/ABC/ACPM/ADA/AGS/APhA/ASPC/NLA/PCNA guideline on the management of blood cholesterol: a report of the American College of Cardiology/American Heart Association Task Force on Clinical Practice guidelines. J Am Coll Cardiol. 2019;73(24):e285e350. doi:10.1016/j.jacc.2018.11.003 
60. Nantsupawat N, Booncharoen A, Wisetborisut A, et al. Appropriate total cholesterol cut-offs for detection of abnormal LDL cholesterol and non-HDL cholesterol among low cardiovascular risk population. Lipids Health Dis. 2019;18(1):28. doi:10.1186/s12944-019-0975-x

61. Unger T, Borghi C, Charchar F, et al. 2020 International Society of Hypertension global hypertension practice guidelines. J Hypertens. 2020;38(6):982-1004. doi:10.1097/HJH.0000000000002453

62. Onder G, Rezza G, Brusaferro S. Case-fatality rate and characteristics of patients dying in relation to COVID-19 in Italy. JAMA. 2020. doi:10.1001/jama.2020.4683

63. Wu Z, McGoogan JM. Characteristics of and important lessons from the coronavirus disease 2019 (COVID-19) outbreak in China: summary of a report of 72314 cases from the Chinese Center for Disease Control and Prevention. JAMA. 2020;323:1239. doi:10.1001/jama.2020.2648

64. Zheng Z, Peng F, Xu B, et al. Risk factors of critical \& mortal COVID-19 cases: a systematic literature review and meta-analysis. J Infect. 2020;81:e16-e25. doi:10.1016/j.jinf.2020.04.021

65. Xiang YT, Yang Y, Li W, et al. Timely mental health care for the 2019 novel coronavirus outbreak is urgently needed. Lancet Psychiatry. 2020;7(3):228-229. doi:10.1016/S2215-0366(20)30046-8
66. World Health Organization. Webinar NCD hard talks: COVID-19 and NCD: deadly interplay and continuity response. Available from: https:// www.who.int/news-room/events/detail/2020/06/11/default-calendar/webi nar-ncd-hard-talks-making-health-systems-deliver-covid-19-and-ncddeadly-interplay-and-continuity-response. Accessed February 15, 2020.

67. Dalton JE, Bolen SD, Mascha EJ. Publication bias: the elephant in the review. Anesth Analg. 2016;123(4):812-813. doi:10.1213/ ANE.0000000000001596

68. Voss PH, Rehfuess EA. Quality appraisal in systematic reviews of public health interventions: an empirical study on the impact of choice of tool on meta-analysis. J Epidemiol Community Health. 2013;67(1):98-104. doi:10.1136/jech-2011-200940

69. Neimann Rasmussen L, Montgomery P. The prevalence of and factors associated with inclusion of non-English language studies in Campbell systematic reviews: a survey and meta-epidemiological study. Syst Rev. 2018;7(1):129. doi:10.1186/s13643-018-0786-6

70. Allen LN, Nicholson BD, Yeung BYT, Goiana-da-Silva F. Implementation of non-communicable disease policies: a geopolitical analysis of 151 countries. Lancet Global Health. 2020;8(1):e50-e58. doi:10.1016/S2214-109X(19)30446-2
Journal of Healthcare Leadership

\section{Publish your work in this journal}

The Journal of Healthcare Leadership is an international, peer-reviewed, open access journal focusing on leadership for the health profession. The journal is committed to the rapid publication of research focusing on but not limited to: Healthcare policy and law; Theoretical and practical aspects healthcare delivery; Interactions between healthcare and society and evidence-based practices; Interdisciplinary decision-making;
Dovepress

Philosophical and ethical issues; Hazard management; Research and opinion for health leadership; Leadership assessment. The manuscript management system is completely online and includes a very quick and fair peer-review system. Visit http://www.dovepress.com/ testimonials.php to read real quotes from published authors. 